\title{
New perspectives in signaling mediated by receptors coupled to stimulatory $G$ protein: the emerging significance of cAMP efflux and extracellular cAMP-adenosine pathway
}

OPEN ACCESS

Edited by:

Claudio M. Costa-Neto, University of Sao Paulo, Brazil

Reviewed by: Antonio Macchiarulo,

University of Perugia, Italy

Lauren Therese May,

Monash University, Australia

${ }^{*}$ Correspondence:

Rosely O. Godinho,

Disciplina Farmacologia Celular, Departamento de Farmacologia,

Escola Paulista de Medicina, Universidade Federal de São Paulo, Rua Três de Maio 100, 3rd Floor, Vila

Clementino, São Paulo, SP 04044-020, Brazil godinho@unifesp.br

Specialty section

This article was submitted to Experimental Pharmacology and Drug

Discovery, a section of the journal Frontiers in Pharmacology

Received: 07 January 2015 Paper pending published: 10 February 2015 Accepted: 06 March 2015 Published: 25 March 2015

Citation:

Godinho RO, Duarte T and Pacin

ESA (2015) New perspectives in

signaling mediated by receptors coupled to stimulatory $G$ protein: the emerging significance of CAMP efflux and extracellular CAMP-adenosine

Front. Pharmacol. 6:58. doi: 10.3389/fphar.2015.00058

\author{
Rosely O. Godinho*, Thiago Duarte and Enio S. A. Pacini
}

Disciplina Farmacologia Celular, Departamento de Farmacologia, Escola Paulista de Medicina, Universidade Federal de São Paulo, São Paulo, Brazil

G protein-coupled receptors (GPCRs) linked to stimulatory $G(G s)$ proteins (GsPCRs) mediate increases in intracellular cyclic AMP as consequence of activation of nine adenylyl cyclases, which differ considerably in their cellular distribution and activation mechanisms. Once produced, cyclic AMP may act via distinct intracellular signaling effectors such as protein kinase $A$ and the exchange proteins activated by CAMP (Epacs). More recently, attention has been focused on the efflux of cAMP through a specific transport system named multidrug resistance proteins that belongs to the ATPbinding cassette transporter superfamily. Outside the cell, cAMP is metabolized into adenosine, which is able to activate four distinct subtypes of adenosine receptors, members of the GPCR family: $A_{1}, A_{2 A}, A_{2 B}$, and $A_{3}$. Taking into account that this phenomenon occurs in numerous cell types, as consequence of GsPCR activation and increment in intracellular cAMP levels, in this review, we will discuss the impact of CAMP efflux and the extracellular cAMP-adenosine pathway on the regulation of GsPCR-induced cell response.

Keywords: G protein-coupled receptors, cyclic AMP, cAMP efflux, adenosine, adenosine receptors, ABC transporters, ecto-phosphodiesterase, ecto-5'-nucleotidase

Seven transmembrane receptors are able to transmit extracellular signals into the intracellular compartment via activation of heterotrimeric $\mathrm{G}$ proteins, which consist of the guanine nucleotidebinding $\mathrm{G} \alpha$ subunit and the dimeric $\beta \gamma$ subunits (Pierce et al., 2002). These $G$ protein-coupled receptors (GPCRs) are ubiquitously distributed and precisely regulate a myriad of intracellular processes upon agonist stimulation. GPCRs may also activate $\beta$-arrestin-dependent signaling, which functions as an adaptor protein that regulates GPCR signaling and trafficking, having the ability to activate intracellular pathways independently of G proteins (DeWire et al., 2007).

The membrane-associated $G$ proteins can be divided into four families according to the primary

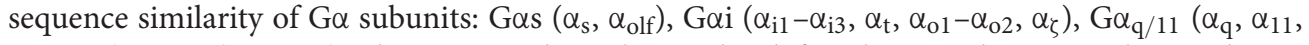
$\left.\alpha_{14}-\alpha_{16}\right), G \alpha_{12}\left(\alpha_{12}, \alpha_{13}\right)$. The sequence homologies also define the $\mathrm{G} \alpha$ subunit coupling to downstream effector molecules, such as phospholipase C- $\beta$, adenylyl cyclase (AC), RhoGEFs and/or ion channels (Moreira, 2014). 
Conformational changes of GPCR, induced by extracellular agonist binding, reduces the affinity of GDP to G $\alpha$ subunit, resulting in sequential dissociation of GDP-G $\alpha$ complex, interaction of GTP with $\mathrm{G} \alpha$, and dissociation of heterotrimeric complex $\mathrm{G} \alpha-\beta \gamma$ into $\mathrm{G} \alpha$ subunit and $\beta \gamma$ dimmer (Pierce et al., 2002). Focusing on activation of GPCRs linked to stimulatory G (Gs) proteins (GsPCR), the GTP-Gas complex is able to interact and activate all available membrane bound $\mathrm{AC}$ isoforms (AC1-AC9), increasing the intracellular generation of adenosine $3^{\prime}, 5^{\prime}$-cyclic monophosphate $\left(3^{\prime}, 5^{\prime}\right.$ cAMP or cAMP). Conversely, by activating inhibitory $\mathrm{G}$ (Gi) protein, agonists of GiPCR elicit the selective inhibition of $\mathrm{AC} 1, \mathrm{AC5}$, and AC6, reducing the intracellular cAMP content (Sadana and Dessauer, 2009).

Cyclic AMP was first described by Rall et al. (1957) who showed that sympathomimetic amines and glucagon were able to induce the synthesis of a heat-stable factor formed by particulate fractions of liver homogenates in the presence of ATP and $\mathrm{Mg}^{2+}$. Identified as adenine ribonucleotide, the compound was identical to the cAMP described by Cook et al. (1957) at the same year. Since then, intracellular signaling through cAMP has been described in virtually every cell (Antoni, 2012). The protein kinase A (PKA), a serine/threonine kinase ubiquitously expressed in mammal tissues, was the first cAMP downstream target to be identified (Walsh et al., 1968). Formed by two regulatory and two catalytic subunits, activation of PKA involves the cooperative binding of four cAMP molecules to two regulatory subunits, leading the catalytic subunits free to phosphorylate target proteins. Intracellular cAMP is also able to directly modulate ion channels (Bradley et al., 2005), such as the hyperpolarization-activated cyclic nucleotide-gated channels (HCN channels) expressed in the cardiac sinoatrial node (Larsson, 2010). Additionally, exchange proteins directly activated by cAMP (Epac) explained various effects of cAMP that could not be attributed to the PKA or CAMP-gated ion channels (Gloerich and Bos, 2010).

\section{Phosphodiesterases, MRP/ABCC Transporters and CAMP Efflux}

The fine regulation of intracellular cAMP signaling is made by phosphodiesterases (PDEs), enzymes that catalyze the hydrolysis of cAMP into AMP. Actually, the superfamily of PDE enzymes is comprised of 11 families, namely PDE1-PDE11. While PDE4, PDE7, and PDE8 are specific for cAMP, PDE5-PDE6, and PDE9 are specific for guanosine $3^{\prime}, 5^{\prime}$-cyclic monophosphate (cGMP) and PDE1-PDE3 and PDE10-PDE11 hydrolyze both cAMP and cGMP (Bender and Beavo, 2006; Francis et al., 2011). By hydrolyzing the cyclic nucleotide monophosphates, PDEs regulate several important physiological processes, such as vascular resistance, cardiac output, visceral motility, immune response, inflammation, neuroplasticity, vision, and reproduction (Azevedo et al., 2014). Therefore, altered expression of PDE or changes in the enzyme activity have been associated with a number of pathological conditions, including erectile dysfunction, pulmonary hypertension, acute refractory cardiac failure, chronic obstructive pulmonary disease and various types of cancer (Azevedo et al., 2014).

In addition to PDE, the intracellular concentration of cAMP is regulated by its efflux into the extracellular space through a specific transport system named multidrug resistance proteins (MRP; Cheepala et al., 2013) that belongs to the ATP-binding cassette $(\mathrm{ABC})$ transporter superfamily (subfamily $C$ ). Three of them (MRP4/ABCC4, MRP5/ABCC5, and MRP8/ABCC11) have the ability to actively extrude cAMP and cGMP from the cell (Kruh and Belinsky, 2003) with different kinetic parameters (Km values in the $\mu \mathrm{M}$ range; Jedlitschky et al., 2000; Chen et al., 2001; Guo et al., 2003; Sager and Ravna, 2009).

The MRP-mediated cAMP efflux has been shown in many cell types, including rodent skeletal muscle (Godinho and Costa, 2003), human platelets (Jedlitschky et al., 2004) vascular smooth muscle cells (Sassi et al., 2008; Cheng et al., 2010), pulmonary arteries (Hara et al., 2011) and cardiac myocytes (Sassi et al., 2011). Therefore, it was proposed that by working synergistically with PDE enzymes, MRP-mediated cAMP efflux would preserve the cell from excessive levels of intracellular cAMP (Jedlitschky et al., 2000; Chen et al., 2001). Although reasonable, this premise was not consistent with the high energetic cost of pumping cAMP out of cell (Godinho and Costa, 2003; Chiavegatti et al., 2008). Thus, it was hypothesized that cAMP might also function as an extracellular signaling molecule (Jackson and Raghvendra, 2004). In fact, since the middle 1960s, extracellular effects of cAMP have been reported in different mammal tissues and organs. For example, intravenous infusion of cAMP is known to produce a wide range of responses, including increased adrenal corticosterone secretion in hypophysectomized rats (Imura et al., 1965), increment in heart rate, cardiac output, and blood glucose, reduction of blood pressure (Levine and Vogel, 1966) and increment in calcium and phosphate plasma concentration (Rasmussen et al., 1968). cAMP infusion effects seem to be exclusively extracellular since most cells are impermeable to cAMP (Robison et al., 1965).

\section{Ecto-Phosphodiesterases, Ecto- Nucleotidases, and the Extracellular cAMP-Adenosine Pathway}

The idea of an extracellular role for cAMP gained strength in the late 1990s when it was established that extracellular cAMP could be sequentially metabolized into AMP and adenosine, a phenomenon named "extracellular cAMP-adenosine pathway" (Mi and Jackson, 1998). Actually, the existence of ecto-enzymes with PDE activity was first demonstrated in frog skeletal muscle by Woo and Manery (1973), who showed extracellular generation of $\left[{ }^{14} \mathrm{C}\right] \mathrm{AMP}$ as consequence of incubation of intact posterior leg muscles with $\left[{ }^{14} \mathrm{C}\right] \mathrm{cAMP}$. The degradation of cAMP was markedly inhibited by theophylline, suggesting the presence of cAMP-phosphodiesterase activity at the muscle fiber surface (Woo and Manery, 1973). Later, ecto-phosphodiesterase activity was found in rodent liver cells (Smoake et al., 1981), vascular smooth muscles (Dubey et al., 1996; Jackson et al., 1997), adipocytes (Strouch et al., 2005), skeletal muscle (Chiavegatti 
et al., 2008), rat ileum (Giron et al., 2008), astrocytes and microglia (Verrier et al., 2011) and many other cells.

In those cells, following the extracellular degradation of $3^{\prime}, 5^{\prime}$ cAMP by ecto-PDE, $5^{\prime}$-AMP is rapidly hydrolyzed to adenosine by membrane-bound ecto- $5^{\prime}$-nucleotidases (EC 3.1.3.5), also known as CD73. The ecto- $5^{\prime}$-nucleotidase is a $70-\mathrm{kDa}$ cell surface glycoprotein found in most tissues that functions as the major enzymatic source of interstitial adenosine (Colgan et al., 2006). Although ecto- $5^{\prime}$-nucleotidases also hydrolyzes other riboand deoxyribonucleoside $5^{\prime}$-monophosphates including cytidine, uridine-, inosine-, and guanosine- $5^{\prime}$-monophosphates, AMP is the most effectively hydrolyzed nucleotide (Zimmermann et al., 2012). Thus, by hydrolyzing 5'-AMP derived from either ATP or cAMP, ecto-5' -nucleotidases act as a limiting point for the extracellular provision of adenosine and, as consequence, for activation of adenosine receptors (ARs).

In addition to ecto- $5^{\prime}$-nucleotidases, other three types of surface-located ecto-nucleotidases are involved in the extracellular nucleosides degradation and, consequently, in the extracellular adenosine formation: ecto-nucleoside triphosphate diphosphohydrolases (EC 3.6.1.5), ecto-nucleotide pyrophosphatase/PDEs (EC 3.6.1.9 and EC 3.1.4.1) and alkaline phosphatases (APs; EC 3.1.3.1). While ecto- $5^{\prime}$-nucleotidases is nucleotide-specific, ecto-nucleotide pyrophosphatase/PDEs and ecto-nucleoside triphosphate diphosphohydrolases hydrolyze both ATP and ADP (Zimmermann et al., 2012).

\section{Adenosine Receptors and the Extracellular cAMP-Adenosine Pathway}

The extracellular degradation of cAMP allows the activation of membrane associated ARs by its metabolite adenosine. Pharmacologically, four distinct subtypes of ARs, members of the GPCR family, are described: $A_{1}, A_{2 A}, A_{2 B}$, and $A_{3}$ (Fredholm et al., 2011). These receptors have a very broad tissue distribution, performing relevant physiological effects in central nervous system (Ribeiro et al., 2002; Wei et al., 2011), cardiovascular (Headrick et al., 2013; Idzko et al., 2014a) and musculoskeletal systems (Burnstock et al., 2013) and many other tissues (Vallon et al., 2006; Sheth et al., 2014). Activation of adenosine is also involved in pathophysiological conditions such as cancer, inflammation (Antonioli et al., 2013; Idzko et al., 2014b) and neurodegenerative diseases, with potential therapeutic implications for Parkinson's and Alzheimer's diseases (Ribeiro et al., 2002).

AR subtypes exhibit different affinities for the endogenous agonist (Muller and Jacobson, 2011): $A_{1}, A_{2 A}$, and $A_{3}$ display high to moderate affinity $(\mathrm{Ki}=100,310$, and $290 \mathrm{nM}$, respectively) to adenosine whereas $\mathrm{A}_{2 \mathrm{~B}}$ has low affinity $(\mathrm{Ki}=15 \mu \mathrm{M})$. Furthermore, distinct signaling transduction pathways are mobilized by each $A R$, leading to diverse cellular effects. The $A_{1}$ and $\mathrm{A}_{3}$ are preferentially coupled to the Gi/o family of G-proteins whereas the $A_{2 A}$ and $A_{2 B}$ couple to Gs proteins (Trincavelli et al., 2010). Thus, as shown in Figure 1, depending on the receptor subtypes expressed in the cell, the extracellular cAMP-adenosine pathway will be able to increase (Figure 1A) or attenuate
(Figure 1B) the intracellular cAMP production, by activating or inhibiting ACs, via Gs and Gi proteins, respectively. Therefore, the final biological effect of the extracellular cAMP-adenosine pathway will depend on AR subtype expressed by the target cell and on the amount of cAMP pumped out of the cell.

In fact, the extracellular cAMP-adenosine signaling can be even more complex, as in addition to classical Gs and Gi pathways, $A R$ subtypes can also activate $G q$ protein $\left(A_{2 B}\right.$ and $\left.A_{3}\right)$, phospholipase C- $\beta\left(A_{1}, A_{2 B}\right.$, and $\left.A_{3}\right), \operatorname{PKC}\left(A_{2 B}\right.$ and $\left.A_{3}\right), K_{A T P}$ channel $\left(\mathrm{A}_{3}\right)$, and $\operatorname{ERK} 1 / 2\left(\mathrm{~A}_{1}, \mathrm{~A}_{2 \mathrm{~A}} / \mathrm{A}_{2 \mathrm{~B}}\right.$, and $\left.\mathrm{A}_{3}\right)$ p38 $\left(\mathrm{A}_{1}\right.$ and $A_{2 B}$ ) MAPK cascade (Feoktistov et al., 1999; Schulte and Fredholm, 2003), which in turn are able to modulate AC activation (Sadana and Dessauer, 2009).

\section{Activation of GsPCR and the Extracellular cAMP-Adenosine Pathway}

Taking into account that cAMP may function as an extracellular signaling molecule, it is possible to assume that, by stimulating AC enzymes, all GsPCRs may have significant impact on cAMP efflux and extracellular cAMP-adenosine signaling. Actually, by studying the contribution of cAMP efflux and the extracellular CAMP-adenosine pathway on skeletal muscle physiology, we showed that cAMP egress induced by activation of GsPCR, such as $\beta$-adrenoceptors and calcitonin gene-related peptide receptors, is proportional to intracellular levels of cAMP produced (Godinho and Costa, 2003; Chiavegatti et al., 2008). Of more importance, cAMP efflux and subsequent extracellular generation of adenosine elicited by $\beta_{2}$-adrenoceptor agonists results in a delayed attenuation of $\beta_{2}$-adrenoceptor-induced positive inotropic effect, via activation of $A_{1}$ ARs (Duarte et al., 2012), as schematically shown in Figure 1B.

The correlation of GsPCR activation, cAMP efflux, and the extracellular cAMP-adenosine pathway has been described in many other cells. For example, the $\beta$-adrenoceptor agonist isoproterenol stimulates cAMP secretion from rat cultured glioma cells (Doore et al., 1975) and turkey erythrocytes (Rindler et al., 1978). In mouse adrenocortical tumor cell line, the intracellular cAMP formed in response to ACTH appeared extracellularly in few minutes (Schimmer and Zimmerman, 1976). In healthy volunteers, infusion of glucagon after hepatic venous catheterization was associated with a marked increase in both the splanchnic cAMP production and in the arterial cyclic nucleotide levels (Grill et al., 1979). In addition, while activation of $\mathrm{D}_{1}$ dopamine receptor stimulates cAMP efflux from rat neostriatal cells (Plantie et al., 1983), vasoactive intestinal peptide and cholecystokinin8 cause a significant increase in cAMP efflux from rat striatal slices (O'Shaughnessy et al., 1987). Many other GsPCR agonists are able to stimulate cAMP efflux, such as corticotropin-releasing hormone and melanocortin (de Koning et al., 1992), vasopressin (Tyagi et al., 1998) and pituitary AC activating polypeptide (Cui et al., 2000). Taking into account that cAMP efflux depends on increased intracellular generation of cyclic nucleotide it is possible to presume that cAMP export could be ubiquitously elicited by activation of every GsPCR. 


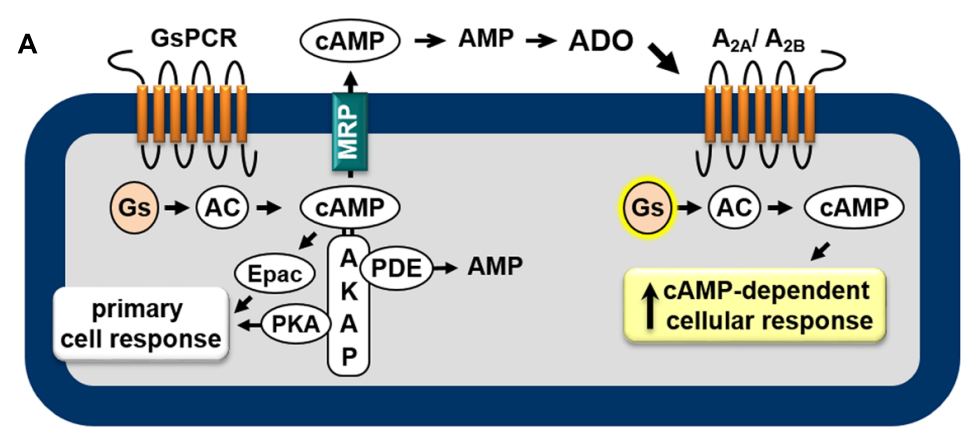

B

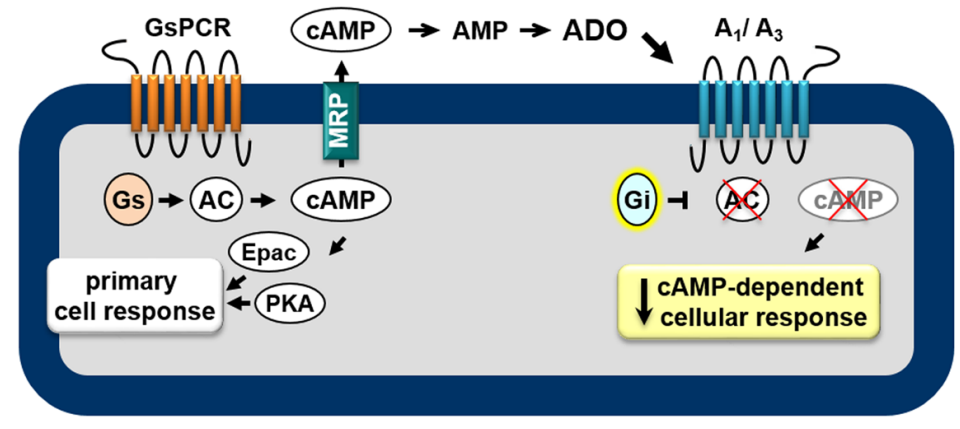

C

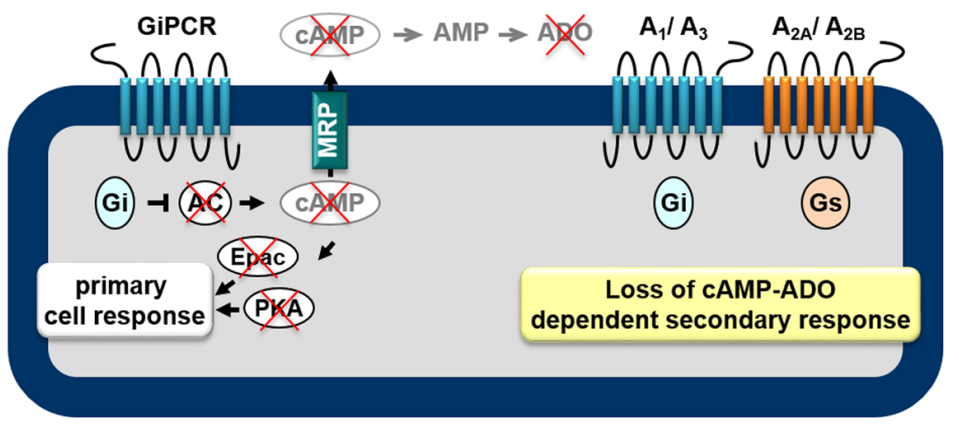

FIGURE 1 | Feedback mechanisms mediated by the extracellular cAMP-adenosine cascade. Activation of receptors coupled to Gs protein (GsPCR) leads to stimulation of adenylyl cyclase (AC) and increased generation of cAMP, which may elicit localized cellular response via activation of effectors such as PKA or Epac (A,B), which are organized in microdomains via anchoring proteins, such as AKAP. cAMP may be hydrolyzed by intracellular phosphodiesterases (PDEs) or may leave the cell via multidrug resistance proteins (MRPs). Outside the cell, ecto-PDE and ecto-5'nucleotidase sequentially convert cAMP to AMP and adenosine (ADO), which may activate Gs-coupled $A_{2 A} / A_{2 B}$ (A) or Gi-coupled $A_{1} / A_{3}$ (B) receptors, increasing or attenuating CAMP production, respectively. In addition, activation of receptors coupled to Gi protein (GiPCR) results in inhibition of Gi-sensitive ACs reducing both generation and efflux of CAMP (C), with consequent loss of autocrine/paracrine feedback signaling of extracellular CAMP.
Conversely, it is also plausible to postulate that by inhibiting Gai-sensitive ACs and reducing intracellular cAMP generation, receptors linked to Gi protein (GiPCR) would be able to negatively modulate cAMP efflux. For instance, cAMP egress from rat neostriatal slices induced by activation of Gs-linked D-1 dopamine receptors is reduced by agonists of $\mathrm{D}_{2}$ receptor agonists (Stoof and Kebabian, 1981), $\mu$ - or $\delta$ opioid receptors (Schoffelmeer et al., 1985) and $\mathrm{M}_{2}$ and $\mathrm{M}_{4}$ muscarinic receptors (Schoffelmeer et al., 1988), known to be coupled to Gi-protein. Indeed, several pheromones and fatty acids, components of membrane phospholipids, also inhibit cAMP export (Kanter et al., 1989) by activating free fatty acid receptors, such as FFA5, linked to Gi/o protein (Wang et al., 2006). Thus, inhibition of cAMP egress as consequence of inhibition of cAMP production may provide an additional mechanism by which GiPCR agonists influence the cAMP signaling pathway, as illustrated in Figure 1C. Table 1 presents a list of GPCR receptors linked to Gs and Gi protein (Alexander et al., 2013) that, by modulating intracellular generation of cAMP, may function as regulators of cAMP efflux and extracellular CAMP adenosine pathway.

Assuming the physiological significance of cAMP efflux and extracellular cAMP-adenosine pathway in modulating GsPCR signaling, impairment of this extracellular feedback mechanism may have profound impact in several physiological processes leading 
TABLE 1 | Receptors coupled to stimulatory (Gs) and inhibitory (Gi) G proteins that might trigger or attenuate the cAMP efflux and the extracellular cAMP-adenosine pathway.

G $\alpha$ subunits

\begin{tabular}{|c|c|}
\hline \multicolumn{2}{|l|}{ Receptors coupled to inhibitory G protein (Gai) } \\
\hline $\begin{array}{l}\text { Orphans: GPR22, GPR34, GPR37, GPR84,1 MRGPRD, GPR33, } \\
\text { GPR37L1, OPN5 }\end{array}$ & Hydroxycarboxylic acid: $\mathrm{HCA}_{1}, \mathrm{HCA}_{2}, \mathrm{HCA}_{3}$ \\
\hline Acetylcholine (Muscarinic): $\mathrm{M}_{2}, \mathrm{M}_{4}$ & 5-Hydroxytryptamine: $5-\mathrm{HT}_{1 \mathrm{~A}}, 5-\mathrm{HT}_{1 \mathrm{~B}}, 5-\mathrm{HT}_{1 \mathrm{D}}-5-\mathrm{HT}_{1 \mathrm{~F}}, 5-\mathrm{Ht}_{5 \mathrm{~A}}$ \\
\hline Adenosine: $A_{1}, A_{3}$ & Leukotriene/lipoxin/oxoeicosanoids: $\mathrm{BLT}_{1}-\mathrm{BLT}_{2}, \mathrm{FPR}_{2} / \mathrm{ALX}, \mathrm{OXE}$ \\
\hline Adrenoceptor $(\alpha): \alpha_{2 A}, \alpha_{2 B}, \alpha_{2 C}$ & Lysophospholipid (LPA): $\mathrm{LPA}_{1}-\mathrm{LPA}_{4}$ \\
\hline Angiotensin: $\mathrm{AT}_{2}$ & Sphingosine 1-phosphate (S1P): $\mathrm{S}_{1} \mathrm{P}_{1}, \mathrm{~S}_{1} \mathrm{P}_{3}-\mathrm{S}_{1} \mathrm{P}_{5}$ \\
\hline Apelin: HGNC & Melanin-concentrating hormone (MCH): $\mathrm{MCH}_{1}$ \\
\hline Calcium sensing: $\mathrm{CaS}$ & Melatonin: $\mathrm{MT}_{1}-\mathrm{MT}_{2}$ \\
\hline Cannabinoid: $\mathrm{CB}_{1}, \mathrm{CB}_{2}$ & Metabotropic glutamate (mGlu): $m G_{1} u_{2}-m_{G l u_{4}} ; m G l u_{6}-m G l u_{8}$ \\
\hline Chemokine: $\mathrm{CCR}_{1}-\mathrm{CCR}_{10}, \mathrm{CXCR}_{1}-\mathrm{CXCR}_{6}, \mathrm{CX}_{3} \mathrm{CR} 1, \mathrm{XCR} 1$ & Neuropeptide FF/neuropeptide AF: NPFF2 \\
\hline Complement peptide: $\mathrm{C} 3 \mathrm{a}, \mathrm{C} 5 \mathrm{a}_{1}$ & Neuropeptide W/neuropeptide B: NPBW1-NPBW2 \\
\hline Dopamine: $D_{2}, D_{3}, D_{4}$ & Neuropeptide $Y: Y_{1}-Y_{2}, Y_{4}-Y_{6}$ \\
\hline Endothelin: $E T_{B}$ & Opioid: $\delta, \kappa, \mu, N O P$ \\
\hline Estrogen (G protein-coupled): GPER & Purinergic P2Y: $\mathrm{P}_{2} \mathrm{Y}_{12}-\mathrm{P} 2 \mathrm{Y}_{13}$ \\
\hline Formylpeptide: FPR1, FPR2/ALX & Peptide P518: QRFP \\
\hline Free fatty acid: FFA3, FFA2, FFA5 & Platelet-activating factor: $\mathrm{PAF}$ \\
\hline Gaba: Gaba & Prostanoid: $\mathrm{DP}_{2}, \mathrm{EP}_{3}$ \\
\hline Galanin: $\mathrm{GAL}_{1}, \mathrm{GAL}_{2}, \mathrm{GAL}_{3}$ & Proteinase-activated (PARs): PAR1, PAR2, PAR4 \\
\hline Glycoprotein hormone: TSH, LH & Relaxin family peptide (RXFP): RXFP3-RXFP4 \\
\hline GPR18 (provisional nomenclature) & Somatostatin (sst): sst $_{1}-s s t_{5}$ \\
\hline Histamine: $\mathrm{H}_{3}, \mathrm{H}_{4}$ & Vasopressin and Oxytocin: ОТ \\
\hline \multicolumn{2}{|l|}{ Receptors coupled to stimulatory G protein (G $\alpha \mathbf{s})$} \\
\hline $\begin{array}{l}\text { Orphans: GPR3-GPR4, GPR6, GPR26, GPR61, GPR65, GPR132, TAAR2, } \\
\text { GPR78, GPR174 }\end{array}$ & Histamine: $\mathrm{H}_{2}$ \\
\hline 5-Hydroxytryptamine: $5-\mathrm{HT}_{4}, 5-\mathrm{HT}_{6}-5-\mathrm{HT}_{7}$ & Lysophospholipid (LPA): $\mathrm{LPA}_{3}-\mathrm{LPA}_{4}$ \\
\hline Adenosine: $A_{2 A}, A_{2 B}$ & Sphingosine 1-phosphate (S1P): $\mathrm{S}_{1} \mathrm{P}_{2}-\mathrm{S}_{1} \mathrm{P}_{4}$ \\
\hline Adrenoceptor ( $\beta): \beta_{1}-\beta_{3}$ & Melanocortin: $\mathrm{MC}_{1}-\mathrm{MC}_{5}$ \\
\hline Bile acid & Neuropeptide S: NPS \\
\hline Calcitonin: $C G R P, A M_{1}-A M_{2}, C T, A M Y_{1}-A M Y_{3}$, & Purinergic P2Y: $\mathrm{P}_{2} \mathrm{Y}_{11}$ \\
\hline Cholecystokinin: $\mathrm{CCK}_{1}, \mathrm{CCK}_{2}$ & Parathyroid hormone: $\mathrm{PTH}_{1}-\mathrm{PTH}_{2}$ \\
\hline Corticotropin-releasing factor: $\mathrm{CRF}_{1}, \mathrm{CRF}_{2}$ & Prostanoid: $\mathrm{DP}_{1}, \mathrm{EP}_{2}, \mathrm{EP}_{4}$ \\
\hline Dopamine: $D_{1}, D_{5}$ & Relaxin family peptide (RXFP): RXFP1-RXFP2 \\
\hline Endothelin: $\mathrm{ET}_{\mathrm{A}}$ & Trace Amino: $\mathrm{TA}_{1}$ \\
\hline Estrogen (G protein-coupled): GPER & Vasopressin and Oxytocin receptors: $V_{2}$ \\
\hline Glucagon: glucagon, GLP-1-GLP-2, GIP, GHRH, secretin & Vasoactive intestinal peptide and PACAP: $\mathrm{VPAC}_{1}, \mathrm{VPAC}_{2}, \mathrm{PAC}_{1}$ \\
\hline
\end{tabular}

Glycoprotein hormone: FSH, LH

Based on Alexander et al. (2013).

to pathological conditions associated to cardiovascular, muscular and endocrine disorders and/or inflammatory diseases. For example, cAMP secreted from cardiomyocytes attenuates the development of hypertrophy and fibrosis induced by continuous activation of $\beta_{2}$-adrenoceptors (Sassi et al., 2014). Similarly, cAMP efflux induced by prolong stimulation of $\beta_{2}$-adrenoceptors attenuates skeletal muscle contraction, preserving muscle from deleterious effects of massive $\mathrm{Ca}^{2+}$ release from the sarcoplasmic reticulum (Duarte et al., 2012). In pancreatic acinar cells, cAMP egression through MRP4 clearly attenuates the development of acute pancreatitis induced by caerulein (Ventimiglia et al., 2015). On the other hand, inhibition of cAMP efflux with probenecid reduces bovine sperm capacitation (Osycka-Salut et al., 2014). Finally, the extracellular cAMP-adenosine pathway is able to exert immunoregulatory effects by modulating monocyte function and differentiation through $\mathrm{A}_{2 \mathrm{~A}} / \mathrm{A}_{2 \mathrm{~B}}$ receptors (Sciaraffia et al., 2014), which is consistent with the marked reduction of ecto5 -nucleotidases expression in lymphocytes from patients with a variety of immunodeficiency diseases (Resta et al., 1998). Interestingly, certain antioxidants derived from plants such as the flavonoid quercetin, have been found to inhibit cAMP efflux transporters (Pavan et al., 2015), which open new perspectives in the use of natural products as regulators of extracellular cAMP signaling for therapeutic purposes.

\section{cAMP Signaling Microdomains}

The compartmentalized expression of cAMP signaling components such as GPCR, AC, PKA, and Epacs (Laflamme and Becker, 
1999; Zaccolo, 2009; Terrin et al., 2012) allows the establishment of multiple intracellular cAMP subcompartments. For example, PDEs bind to A kinase-anchoring proteins (AKAPs) forming a PKA-PDE-AKAP complex (Stangherlin and Zaccolo, 2011; Terrin et al., 2012). Likewise, specific AC isoforms have been identified as components of AKAP complexes (Dessauer, 2009), contributing to intracellular compartmentalization of cAMP signaling. In fact, localized expression of ACs generate specific microdomains of elevated concentration of cAMP ensuring signaling specificity, such as those observed in the transverse tubule/junctional sarcoplasmic reticulum network of cardiac and skeletal muscle (Gao et al., 1997; Zaccolo et al., 2002; Menezes-Rodrigues et al., 2013).

Interestingly, the localized expression of MRPs may also play an important role in the intra- and extracellular cAMP signaling process (Cheepala et al., 2013). For example, in the gut epithelia signal compartmentalization of cAMP with MRP4 is essential for cAMP-dependent regulation of chloride channel function ( $\mathrm{Li}$ et al., 2007). As well, contraction of cardiac myocytes induced by activation of $\beta$-adrenoceptor/AC/cAMP cascade can be locally regulated by MRP4 (Sellers et al., 2012). In addition, in vascular smooth muscle cells, MRP4 was found in caveolin-rich membrane fractions regulating CAMP/PKA/CREB pathway cascade (Sassi et al., 2008). Thus, multiprotein signaling complexes, which include MRPs may affect the final GsPCR/cAMP-dependent cellular response. Of more importance, the compartmentalized expression of ARs in caveolae/cholesterol-rich microdomains (Sitaraman et al., 2002; Cordeaux et al., 2008; Garg et al., 2009; Assaife-Lopes et al., 2010) suggests that colocalization of MRP4 and ARs in caveolae microdomains coordinates the cAMP efflux in the vicinity of the AR domain (Xie et al., 2011; D' Ambrosi and Volonte, 2013).

On the other hand, activation of ARs involved in the extracellular cAMP-adenosine pathway also depends on the availability and distribution of the ecto-enzymes. Ecto-phosphodiesterase and ecto-nucleotidases or adenosine deaminase can very rapidly modulate the extracellular concentrations of adenosine, which

\section{References}

Alexander, S. P., Benson, H. E., Faccenda, E., Pawson, A. J., Sharman, J. L., Spedding, M., et al. (2013). The Concise guide to PHARMACOLOGY 2013/14: g protein-coupled receptors. Br. J. Pharmacol. 170, 1459-1581. doi: 10.1111/bph.12445

Antoni, F. A. (2012). New paradigms in cAMP signalling. Mol. Cell. Endocrinol. 353, 3-9. doi: 10.1016/j.mce.2011.10.034

Antonioli, L., Blandizzi, C., Pacher, P., and Hasko, G. (2013). Immunity, inflammation and cancer: a leading role for adenosine. Nat. Rev. Cancer 13, 842-857. doi: $10.1038 / \mathrm{nrc} 3613$

Assaife-Lopes, N., Sousa, V. C., Pereira, D. B., Ribeiro, J. A., Chao, M. V., and Sebastiao, A. M. (2010). Activation of adenosine A2A receptors induces TrkB translocation and increases BDNF-mediated phospho-TrkB localization in lipid rafts: implications for neuromodulation. J. Neurosci. 30, 8468-8480. doi: 10.1523/JNEUROSCI.5695-09.2010

Azevedo, M. F., Faucz, F. R., Bimpaki, E., Horvath, A., Levy, I., de Alexandre, R. B., et al. (2014). Clinical and molecular genetics of the phosphodiesterases (PDEs). Endocr. Rev. 35, 195-233. doi: 10.1210/er. 2013-1053 will directly affect receptor subtype activation, and as consequence, the final cell response. Interestingly, while all human AR subtypes contain the caveolin binding domain (Mundell and Kelly, 2011), studies analyzing the subcellular distribution of $A_{1}$ receptors on cardiomyocytes showed that selective activation of $A_{1}$ receptors with $C C P A$ results in the switch of $A_{1}$ receptor from caveolin-3-enriched domains to the bulk plasma membrane (Lasley, 2011). The lipid raft localization of $A_{1}$ receptor seems to be essential for the $A_{1}$-dependent activation of $K_{A T P}$ channels that is involved in cardioprotective effects of adenosine. Disruption of cholesterol-rich microdomains with methylcyclodextrin drastically reduces the effect of ARs on rat ventricular myocytes $\mathrm{K}_{\text {ATP }}$ channels (Garg et al., 2009; D’ Ambrosi and Volonte, 2013).

\section{Conclusion}

The existence of a system involved in sequential extrusion and extracellular degradation of cAMP definitively extend the intracellular signaling relevance of cAMP to an extracellular level, which allows paracrine and/or autocrine feedback signaling, depending on the AR subtype expressed on the target and neighboring cells. In view of the recognized ability of adenosine to regulate many cellular processes (Burnstock, 2007), the existence of the extracellular CAMP-adenosine reveals new insights into the regulatory mechanisms of cellular response triggered by GsPCR and provides novel therapeutic targets for treatment of a number of diseases associated with dysfunction of GPCR signaling cascade.

\section{Acknowledgments}

We thank Dr. Marcelo Funke and Fernanda Eloi for helpful comments on the manuscript. This work was supported by Fapesp (2011/01519-4; 2012/20148-0) and CNPq to RG, TD, and EP are Ph.D fellow from Capes and CNPq.

Bender, A. T., and Beavo, J. A. (2006). Cyclic nucleotide phosphodiesterases: molecular regulation to clinical use. Pharmacol. Rev. 58, 488-520. doi: 10.1124/pr.58.3.5

Bradley, J., Reisert, J., and Frings, S. (2005). Regulation of cyclic nucleotidegated channels. Curr. Opin. Neurobiol. 15, 343-349. doi: 10.1016/j.conb.2005. 05.014

Burnstock, G. (2007). Purine and pyrimidine receptors. Cell. Mol. Life Sci. 64, 1471-1483. doi: 10.1007/s00018-007-6497-0

Burnstock, G., Arnett, T. R., and Orriss, I. R. (2013). Purinergic signalling in the musculoskeletal system. Purinergic Signal. 9, 541-572. doi: 10.1007/s11302013-9381-4

Cheepala, S., Hulot, J. S., Morgan, J. A., Sassi, Y., Zhang, W., Naren, A. P., et al. (2013). Cyclic nucleotide compartmentalization: contributions of phosphodiesterases and ATP-binding cassette transporters. Annu. Rev. Pharmacol. Toxicol. 53, 231-253. doi: 10.1146/annurev-pharmtox-010611134609

Chen, Z. S., Lee, K., and Kruh, G. D. (2001). Transport of cyclic nucleotides and estradiol 17-beta-D-glucuronide by multidrug resistance protein 4 . Resistance to 6-mercaptopurine and 6-thioguanine. J. Biol. Chem. 276, 33747-33754. doi: 10.1074/jbc.M104833200 
Cheng, D., Ren, J., and Jackson, E. K. (2010). Multidrug resistance protein 4 mediates cAMP efflux from rat preglomerular vascular smooth muscle cells. Clin. Exp. Pharmacol. Physiol. 37, 205-207. doi: 10.1111/j.1440-1681.2009.05272.x

Chiavegatti, T., Costa, V. L., Araujo, M. S., and Godinho, R. O. (2008). Skeletal muscle expresses the extracellular cyclic AMP-adenosine pathway. Br. J. Pharmacol. 153, 1331-1340. doi: 10.1038/sj.bjp.0707648

Colgan, S. P., Eltzschig, H. K., Eckle, T., and Thompson, L. F. (2006). Physiological roles for ecto- $5^{\prime}$-nucleotidase (CD73). Purinergic Signal. 2, 351-360. doi: 10.1007/s11302-005-5302-5

Cook, W. H., Lipkin, D., and Markham, R. (1957). The formation of a cyclic dianhydrodiadenylic acid (I) by the alkaline degradation of adenosine- $5^{\prime}$-triphosphoric acid (II)1. J. Am. Chem. Soc. 79, 3607-3608. doi: 10.1021/ja01570a086

Cordeaux, Y., Briddon, S. J., Alexander, S. P., Kellam, B., and Hill, S. J. (2008). Agonist-occupied A3 adenosine receptors exist within heterogeneous complexes in membrane microdomains of individual living cells. FASEB J. 22, 850-860. doi: 10.1096/fj.07-8180com

Cui, X., Lee, S. J., Kim, S. Z., Kim, S. H., and Cho, K. W. (2000). Effects of pituitary adenylate cyclase activating polypeptide27 on cyclic AMP efflux and atrial dynamics in perfused beating atria. Eur. J. Pharmacol. 402, 129-137. doi: 10.1016/S0014-2999(00)00514-8

D' Ambrosi, N., and Volonte, C. (2013). Metabotropic purinergic receptors in lipid membrane microdomains. Curr. Med. Chem. 20, 56-63. doi: 10.2174/0929867311302010007

de Koning, H. P., Jenks, B. G., Huchede, B., and Roubos, E. W. (1992). Dynamics of cyclic-AMP efflux in relation to alpha-MSH secretion from melanotrope cells of Xenopus laevis. Life Sci. 51, 1667-1673. doi: 10.1016/0024-3205(92)90311-C

Dessauer, C. W. (2009). Adenylyl cyclase-A-kinase anchoring protein complexes: the next dimension in cAMP signaling. Mol. Pharmacol. 76, 935-941. doi: 10.1124/mol.109.059345

DeWire, S. M., Ahn, S., Lefkowitz, R. J., and Shenoy, S. K. (2007). Beta-arrestins and cell signaling. Annu. Rev. Physiol. 69, 483-510. doi: 10.1146/annurev.physiol.69.022405.154749

Doore, B. J., Bashor, M. M., Spitzer, N., Mawe, R. C., and Saier, M. H. Jr. (1975). Regulation of adenosine $3^{\prime}: 5^{\prime}$-monophosphate efflux from rat glioma cells in culture*. J. Biol. Chem. 250, 4371-4372.

Duarte, T., Menezes-Rodrigues, F. S., and Godinho, R. O. (2012). Contribution of the extracellular cAMP-adenosine pathway to dual coupling of beta2adrenoceptors to Gs and Gi proteins in mouse skeletal muscle. J. Pharmacol. Exp. Ther. 341, 820-828. doi: 10.1124/jpet.112.192997

Dubey, R. K., Mi, Z., Gillespie, D. G., and Jackson, E. K. (1996). Cyclic AMPadenosine pathway inhibits vascular smooth muscle cell growth. Hypertension 28, 765-771. doi: 10.1161/01.HYP.28.5.765

Feoktistov, I., Goldstein, A. E., and Biaggioni, I. (1999). Role of p38 mitogenactivated protein kinase and extracellular signal-regulated protein kinase kinase in adenosine A2B receptor-mediated interleukin- 8 production in human mast cells. Mol. Pharmacol. 55, 726-734.

Francis, S. H., Blount, M. A., and Corbin, J. D. (2011). Mammalian cyclic nucleotide phosphodiesterases: molecular mechanisms and physiological functions. Physiol. Rev. 91, 651-690. doi: 10.1152/physrev.00030.2010

Fredholm, B. B., IJzerman, A. P., Jacobson, K. A., Linden, J., and Muller, C. E. (2011). International Union of Basic and Clinical Pharmacology. LXXXI. Nomenclature and classification of adenosine receptors-an update. Pharmacol. Rev. 63, 1-34. doi: 10.1124/pr.110.003285

Gao, T., Puri, T. S., Gerhardstein, B. L., Chien, A. J., Green, R. D., and Hosey, M. M. (1997). Identification and subcellular localization of the subunits of Ltype calcium channels and adenylyl cyclase in cardiac myocytes. J. Biol. Chem. 272, 19401-19407. doi: 10.1074/jbc.272.31.19401

Garg, V., Jiao, J., and Hu, K. (2009). Regulation of ATP-sensitive $\mathrm{K}^{+}$channels by caveolin-enriched microdomains in cardiac myocytes. Cardiovasc. Res. 82, 51-58. doi: 10.1093/cvr/cvp039

Giron, M. C., Bin, A., Brun, P., Etteri, S., Bolego, C., Florio, C., et al. (2008). Cyclic AMP in rat ileum: evidence for the presence of an extracellular cyclic AMP-adenosine pathway. Gastroenterology 134, 1116-1126. doi: 10.1053/j.gastro.2008.01.030

Gloerich, M., and Bos, J. L. (2010). Epac: defining a new mechanism for cAMP action. Annu. Rev. Pharmacol. Toxicol. 50, 355-375. doi: 10.1146/annurev.pharmtox.010909.105714
Godinho, R. O., and Costa, V. L. Jr. (2003). Regulation of intracellular cyclic AMP in skeletal muscle cells involves the efflux of cyclic nucleotide to the extracellular compartment. Br. J. Pharmacol. 138, 995-1003. doi: 10.1038/sj.bjp.0705130

Grill, V., Cerasi, E., and Wahren, J. (1979). Role of cyclic AMP in glucagon-induced stimulation of hepatic glucose output in man. Scand. J. Clin. Lab. Invest. 39, 689-696. doi: 10.3109/00365517909108159

Guo, Y., Kotova, E., Chen, Z. S., Lee, K., Hopper-Borge, E., Belinsky, M. G., et al. (2003). MRP8, ATP-binding cassette C11 (ABCC11), Is a cyclic nucleotide efflux pump and a resistance factor for Fluoropyrimidines $2^{\prime}, 3^{\prime}$ Dideoxycytidine and $9^{\prime}$-(2'-Phosphonylmethoxyethyl)adenine. J. Biol. Chem. 278, 29509-29514. doi: 10.1074/jbc.M304059200

Hara, Y., Sassi, Y., Guibert, C., Gambaryan, N., Dorfmuller, P., Eddahibi, S., et al. (2011). Inhibition of MRP4 prevents and reverses pulmonary hypertension in mice. J. Clin. Invest. 121, 2888-2897. doi: 10.1172/JCI45023

Headrick, J. P., Ashton, K. J., Rose'meyer, R. B., and Peart, J. N. (2013). Cardiovascular adenosine receptors: expression, actions and interactions. Pharmacol. Ther. 140, 92-111. doi: 10.1016/j.pharmthera.2013. 06.002

Idzko, M., Ferrari, D., and Eltzschig, H. K. (2014a). Nucleotide signalling during inflammation. Nature 509, 310-317. doi: 10.1038/nature13085

Idzko, M., Ferrari, D., Riegel, A. K., and Eltzschig, H. K. (2014b). Extracellular nucleotide and nucleoside signaling in vascular and blood disease. Blood 124, 1029-1037. doi: 10.1182/blood-2013-09-402560

Imura, H., Matsukura, S., Matsuyama, H., Setsuda, T., and Miyake, T. (1965). Adrenal steroidogenic effect of adenosine $3^{\prime}, 5^{\prime}$-monophosphate and its derivatives in vivo. Endocrinology 76, 933-937. doi: 10.1210/endo-76-5-933

Jackson, E. K., Mi, Z., Gillespie, D. G., and Dubey, R. K. (1997). Metabolism of cAMP to adenosine in the renal vasculature. J. Pharmacol. Exp. Ther. 283, $177-182$.

Jackson, E. K., and Raghvendra, D. K. (2004). The extracellular cyclic AMPadenosine pathway in renal physiology. Ann. Rev. Physiol. 66, 571-599. doi: 10.1146/annurev.physiol.66.032102.111604

Jedlitschky, G., Burchell, B., and Keppler, D. (2000). The Multidrug resistance protein 5 functions as an ATP-dependent export pump for cyclic nucleotides. J. Biol. Chem. 275, 30069-30074. doi: 10.1074/jbc.M005463200

Jedlitschky, G., Tirschmann, K., Lubenow, L. E., Nieuwenhuis, H. K., Akkerman, J. W., Greinacher, A., et al. (2004). The nucleotide transporter MRP4 (ABCC4) is highly expressed in human platelets and present in dense granules, indicating a role in mediator storage. Blood 104, 3603-3610. doi: 10.1182/blood-2003-124330

Kanter, J. R., Hagey, L. R., and Brunton, L. L. (1989). Inhibition of cyclic AMP efflux by insect pheromones and fatty acids. FEBS Lett. 244, 149-153. doi: 10.1016/0014-5793(89)81181-0

Kruh, G. D., and Belinsky, M. G. (2003). The MRP family of drug efflux pumps. Oncogene 22, 7537-7552. doi: 10.1038/sj.onc.1206953

Laflamme, M. A., and Becker, P. L. (1999). G(s) and adenylyl cyclase in transverse tubules of heart: implications for cAMP-dependent signaling. Am. J. Physiol. 277, H1841-H1848.

Larsson, H. P. (2010). How is the heart rate regulated in the sinoatrial node? Another piece to the puzzle. J. Gen. Physiol. 136, 237-241. doi: 10.1085/jgp.201010506

Lasley, R. D. (2011). Adenosine receptors and membrane microdomains. Biochim. Biophys. Acta 1808, 1284-1289. doi: 10.1016/j.bbamem.2010.09.019

Levine, R. A., and Vogel, J. A. (1966). Cardiovascular and metabolic effects of cyclic adenosine $3^{\prime}, 5^{\prime}$-monophosphate in unanesthetized dogs. J. Pharmacol. Exp. Ther. 151, 262-272.

Li, C., Krishnamurthy, P. C., Penmatsa, H., Marrs, K. L., Wang, X. Q., Zaccolo, M., et al. (2007). Spatiotemporal coupling of cAMP transporter to CFTR chloride channel function in the gut epithelia. Cell 131, 940-951. doi: 10.1016/j.cell.2007.09.037

Menezes-Rodrigues, F. S., Pires-Oliveira, M., Duarte, T., Paredes-Gamero, E. J., Chiavegatti, T., and Godinho, R. O. (2013). Calcium influx through L-type channels attenuates skeletal muscle contraction via inhibition of adenylyl cyclases. Eur. J. Pharmacol. 720, 326-334. doi: 10.1016/j.ejphar.2013.10.009

Mi, Z., and Jackson, E. K. (1998). Evidence for an endogenous cAMP-adenosine pathway in the rat kidney. J. Pharmacol. Exp. Ther. 287, 926-930.

Moreira, I. S. (2014). Structural features of the G-protein/GPCR interactions. Biochim. Biophys. Acta 1840, 16-33. doi: 10.1016/j.bbagen.2013.08.027 
Muller, C. E., and Jacobson, K. A. (2011). Recent developments in adenosine receptor ligands and their potential as novel drugs. Biochim. Biophys. Acta 1808, 1290-1308. doi: 10.1016/j.bbamem.2010.12.017

Mundell, S., and Kelly, E. (2011). Adenosine receptor desensitization and trafficking. Biochim. Biophys. Acta 1808, 1319-1328. doi: 10.1016/j.bbamem.2010.06.007

O'Shaughnessy, C., Poat, J. A., and Turnbull, M. J. (1987). Cyclic AMP efflux from rat striatal slices is enhanced by CCK. Biochem. Pharmacol. 36, 976-979. doi: 10.1016/0006-2952(87)90196-1

Osycka-Salut, C., Diez, F., Burdet, J., Gervasi, M. G., Franchi, A., Bianciotti, L. G., et al. (2014). Cyclic AMP efflux, via MRPs and A1 adenosine receptors, is critical for bovine sperm capacitation. Mol. Hum. Reprod. 20, 89-99. doi: 10.1093/molehr/gat053

Pavan, B., Capuzzo, A., and Forlani, G. (2015). Quercetin and quercetin-3-Oglucoside interact with different components of the cAMP signaling cascade in human retinal pigment epithelial cells. Life Sci. 121, 166-173. doi: 10.1016/j.lfs.2014.11.010

Pierce, K. L., Premont, R. T., and Lefkowitz, R. J. (2002). Signalling: seventransmembrane receptors. Nat. Rev. Mol. Cell. Biol. 3, 639-650. doi: 10.1038/nrm908

Plantie, J. F., Mulder, A. H., and Stoof, J. C. (1983). 3-PPP antagonizes the in vitro effects of D-1 and D-2 dopamine receptor agonists in rat neostriatum. Eur. J. Pharmacol. 91, 317-320. doi: 10.1016/0014-2999(83)90486-7

Rall, T. W., Sutherland, E. W., and Berthet, J. (1957). The relationship of epinephrine and glucagon to liver phosphorylase: IV. Effect of epinephrine and glucagon on the reactivation of phosphorylase in liver homogenates. J. Biol. Chem. 224, 463-475.

Rasmussen, H., Pechet, M., and Fast, D. (1968). Effect of dibutyryl cyclic adenosine $3^{\prime}, 5^{\prime}$-monophosphate, theophylline, and other nucleotides upon calcium and phosphate metabolism. J. Clin. Invest. 47, 1843-1850. doi: 10.1172/JCI105874

Resta, R., Yamashita, Y., and Thompson, L. F. (1998). Ecto-enzyme and signaling functions of lymphocyte CD73. Immunol. Rev. 161, 95-109. doi: 10.1111/j.1600-065X.1998.tb01574.x

Ribeiro, J. A., Sebastiao, A. M., and de, Mendonça, A. (2002). Adenosine receptors in the nervous system: pathophysiological implications. Prog. Neurobiol. 68, 377-392. doi: 10.1016/S0301-0082(02)00155-7

Rindler, M. J., Bashor, M. M., Spitzer, N., and Saier, M. H. Jr. (1978). Regulation of adenosine $3^{\prime}: 5^{\prime}$-monophosphate efflux from animal cells. J. Biol. Chem. 253, 5431-5436.

Robison, G. A., Butcher, R. W., Oye, I., Morgan, H. E., and sutherland, E. W. (1965). The effect of epinephrine on adenosine $3^{\prime}, 5^{\prime}$-phosphate levels in the isolated perfused rat heart. Mol. Pharmacol. 1, 168-177.

Sadana, R., and Dessauer, C. W. (2009). Physiological roles for G protein-regulated adenylyl cyclase isoforms: insights from knockout and overexpression studies. Neurosignals 17, 5-22. doi: 10.1159/000166277

Sager, G., and Ravna, A. W. (2009). Cellular efflux of cAMP and cGMPa question about selectivity. Mini Rev. Med. Chem. 9, 1009-1013. doi: 10.2174/138955709788681654

Sassi, Y., Abi-Gerges, A., Fauconnier, J., Mougenot, N., Reiken, S., Haghighi, K., et al. (2011). Regulation of cAMP homeostasis by the efflux protein MRP4 in cardiac myocytes. FASEB J. 26, 1009-1017. doi: 10.1096/fj.11-194027

Sassi, Y., Ahles, A., Truong, D. J. J., Baqi, Y., Lee, S. Y., Husse, B., et al. (2014). Cardiac myocyte-secreted cAMP exerts paracrine action via adenosine receptor activation. J. Clin. Invest. 124, 5385-5397. doi: 10.1172/JCI74349

Sassi, Y., Lipskaia, L., Vandecasteele, G., Nikolaev, V. O., Hatem, S. N., Cohen, A. F., et al. (2008). Multidrug resistance-associated protein 4 regulates cAMPdependent signaling pathways and controls human and rat SMC proliferation. J. Clin. Invest. 118, 2747-2757. doi: 10.1172/JCI35067

Schimmer, B. P., and Zimmerman, A. E. (1976). Steroidogenesis and extracellular cAMP accumulation in adrenal tumor cell cultures. Mol. Cell. Endocrinol. 4, 263-270. doi: 10.1016/0303-7207(76)90060-5

Schoffelmeer, A. N., Hansen, H. A., Stoof, J. C., and Mulder, A. H. (1985). Inhibition of dopamine-stimulated cyclic AMP efflux from rat neostriatal slices by activation of mu- and delta-opioid receptors: a permissive role for D-2 dopamine receptors. Eur. J. Pharmacol. 118, 363-366. doi: 10.1016/0014-2999(85) 90150-5

Schoffelmeer, A. N., Hogenboom, F., and Mulder, A. H. (1988). M-1 and M-2 muscarinic receptor-mediated inhibition of dopamine-sensitive adenylate cyclase in rat neostriatum: a permissive role for D-2 dopamine receptors. J. Pharmacol. Exp. Ther. 245, 658-663.

Schulte, G., and Fredholm, B. B. (2003). Signalling from adenosine receptors to mitogen-activated protein kinases. Cell. Signal. 15, 813-827. doi: 10.1016/S0898-6568(03)00058-5

Sciaraffia, E., Riccomi, A., Lindstedt, R., Gesa, V., Cirelli, E., Patrizio, M., et al. (2014). Human monocytes respond to extracellular cAMP through A2A and A2B adenosine receptors. J. Biol. 96, 113-122. doi: 10.1189/jlb.3A0513-302RR

Sellers, Z. M., Naren, A. P., Xiang, Y., and Best, P. M. (2012). MRP4 and CFTR in the regulation of cAMP and $\beta$-adrenergic contraction in cardiac myocytes Eur. J. Pharmacol. 681, 80-87. doi: 10.1016/j.ejphar.2012.02.018

Sheth, S., Brito, R., Mukherjea, D., Rybak, L. P., and Ramkumar, V. (2014). Adenosine receptors: expression, function and regulation. Int. J. Mol. Sci. 15, 2024-2052. doi: 10.3390/ijms15022024

Sitaraman, S. V., Wang, L., Wong, M., Bruewer, M., Hobert, M., Yun, C. H., et al. (2002). The adenosine $2 \mathrm{~b}$ receptor is recruited to the plasma membrane and associates with E3KARP and Ezrin upon agonist stimulation. J. Biol. Chem. 277, 33188-33195. doi: 10.1074/jbc.M202522200

Smoake, J. A., McMahon, K. L., Wright, R. K., and Solomon, S. S. (1981). Hormonally sensitive cyclic AMP phosphodiesterase in liver cells. An ectoenzyme. J. Biol. Chem. 256, 8531-8535.

Stangherlin, A., and Zaccolo, M. (2011). Local termination of $3^{\prime}-5^{\prime}$-cyclic adenosine monophosphate signals: the role of A kinase anchoring proteintethered phosphodiesterases. J. Cardiovasc. Pharmacol. 58, 345-353. doi: 10.1097/FJC.0b013e3182214f2b

Stoof, J. C., and Kebabian, J. W. (1981). Opposing roles for D-1 and D-2 dopamine receptors in efflux of cyclic AMP from rat neostriatum. Nature 294, 366-368. doi: 10.1038/294366a0

Strouch, M. B., Jackson, E. K., Mi, Z., Metes, N. A., and Carey, G. B. (2005). Extracellular cyclic AMP-adenosine pathway in isolated adipocytes and adipose tissue. Obes. Res. 13, 974-981. doi: 10.1038/oby.2005.114

Terrin, A., Monterisi, S., Stangherlin, A., Zoccarato, A., Koschinski, A., Surdo, N. C., et al. (2012). PKA and PDE4D3 anchoring to AKAP9 provides distinct regulation of cAMP signals at the centrosome. J. Cell. Biol. 198, 607-621. doi: $10.1083 /$ jcb.201201059

Trincavelli, M. L., Daniele, S., and Martini, C. (2010). Adenosine receptors: what we know and what we are learning. Curr. Top. Med. Chem. 10, 860-877. doi: $10.2174 / 156802610791268756$

Tyagi, M. G., Handa, R. K., Stephen, P. M., and Bapna, J. S. (1998). Vasopressin induces dopamine release and cyclic AMP efflux from the brain of waterdeprived rats: inhibitory effect of vasopressin V2 receptor-mediated phosphorylation. Biol. Signals Recept. 7, 328-336. doi: 10.1159/000014556

Vallon, V., Muhlbauer, B., and Osswald, H. (2006). Adenosine and kidney function. Physiol. Rev. 86, 901-940. doi: 10.1152/physrev.00031.2005

Ventimiglia, M. S., Najenson, A. C., Perazzo, J. C., Carozzo, A., Vatta, M. S., Davio, C. A., et al. (2015). Blockade of multidrug resistance associated proteins aggravates acute pancreatitis and blunts atrial natriuretic factor benefitial effect in rats: role of MRP4/ABCC4. Mol. Med. doi: 10.2119/molmed.2014.00166 [Epub ahead of print].

Verrier, J. D., Exo, J. L., Jackson, T. C., Ren, J., Gillespie, D. G., Dubey, R. K., et al. (2011). Expression of the $2^{\prime}, 3^{\prime}$-cAMP-adenosine pathway in astrocytes and microglia. J. Neurochem. 118, 979-987. doi: 10.1111/j.1471-4159.2011.07392.x

Walsh, D. A., Perkins, J. P., and Krebs, E. G. (1968). An adenosine $3^{\prime}, 5^{\prime}-$ monophosphate-dependant protein kinase from rabbit skeletal muscle. J. Biol. Chem. 243, 3763-3765.

Wang, J., Wu, X., Simonavicius, N., Tian, H., and Ling, L. (2006). Medium-chain fatty acids as ligands for orphan G protein-coupled receptor GPR84. J. Biol. Chem. 281, 34457-34464. doi: 10.1074/jbc.M608019200

Wei, C. J., Li, W., and Chen, J. F. (2011). Normal and abnormal functions of adenosine receptors in the central nervous system revealed by genetic knockout studies. Biochim. Biophys. Acta 1808, 1358-1379. doi: 10.1016/j.bbamem.2010.12.018

Woo, Y. T., and Manery, J. F. (1973). Cyclic AMP phosphodiesterase activity at the external surface of intact skeletal muscles and stimulation of the enzyme by insulin. Arch. Biochem. Biophys. 154, 510-519. doi: 10.1016/00039861(73)90003-9

Xie, M., Rich, T. C., Scheitrum, C., Conti, M., and Richter, W. (2011). Inactivation of multidrug resistance proteins disrupts both cellular extrusion 
and intracellular degradation of cAMP. Mol. Pharmacol. 80, 281-293. doi: $10.1124 / \mathrm{mol} .111 .071134$

Zaccolo, M. (2009). cAMP signal transduction in the heart: understanding spatial control for the development of novel therapeutic strategies. Br. J. Pharmacol. 158, 50-60. doi: 10.1111/j.1476-5381.2009.00185.x

Zaccolo, M., Magalhaes, P., and Pozzan, T. (2002). Compartmentalisation of cAMP and $\mathrm{Ca}\left(2^{+}\right)$signals. Curr. Opin. Cell. Biol. 14, 160-166. doi: 10.1016/S09550674(02)00316-2

Zimmermann, H., Zebisch, M., and Strater, N. (2012). Cellular function and molecular structure of ecto-nucleotidases. Purinergic Signal. 8, 437-502. doi: $10.1007 /$ s11302-012-9309-4
Conflict of Interest Statement: The authors declare that the research was conducted in the absence of any commercial or financial relationships that could be construed as a potential conflict of interest.

Copyright (c) 2015. Godinho, Duarte and Pacini. This is an open-access article distributed under the terms of the Creative Commons Attribution License (CC BY). The use, distribution or reproduction in other forums is permitted, provided the original author(s) or licensor are credited and that the original publication in this journal is cited, in accordance with accepted academic practice. No use, distribution or reproduction is permitted which does not comply with these terms. 